\title{
Momentum Effects in Steady Nucleate Pool Boiling During Microgravity
}

\author{
HERMAN MERTE, JR.
}

Mechanical Engineering Department, University of Michigan, Ann Arbor, Michigan, USA

\begin{abstract}
Pool boiling experiments were conducted in microgravity on five space shuttle flights, using a flat plate heater consisting of a semitransparent thin gold film deposited on a quartz substrate that also acted as a resistance thermometer. The test fluid was R-113, and the vapor bubble behavior at the heater surface was photographed from beneath as well as from the side. Each flight consisted of a matrix of three levels of heat flux and three levels of subcooling. In 26 of the total of 45 experiments conditions of steady-state pool boiling were achieved under certain combinations of heat flux and liquid subcooling. In many of the 26 cases, it was observed from the 16-mm movie films that a large vapor bubble formed, remaining slightly removed from the heater surface, and that subsequent vapor bubbles nucleate and grow on the heater surface. Coalescence occurs upon making contact with the large bubble, which thus acts as a vapor reservoir. Recently, measurements of the frequencies and sizes of the small vapor bubbles as they coalesced with the large bubble permitted computation of the associated momentum transfer. The transient forces obtained are presented here. Where these arise from the conversion of the surface energy in the small vapor bubble to kinetic energy acting away from the solid heater surface, they counter the Marangoni convection due to the temperature gradients normal to the heater surface. This Marangoni convection would otherwise impel the large vapor bubble toward the heater surface and result in dryout and unsteady heat transfer.
\end{abstract}

KEYWORDS: pool boiling; microgravity; momentum effects

NOMENCLATURE:

D bubble diameter

E $\quad$ surface energy of bubble

$f \quad$ frequency

$F \quad$ force

$m \quad$ mass of bubble

$n_{t} \quad$ total number of bubble sizes considered

$t \quad$ time

$V \quad$ velocity

Greek Symbols

$\rho \quad$ density

$\sigma \quad$ surface tension

Subscripts

$b \quad$ bubble

$i \quad$ index for size

$v \quad$ vapor

Address for correspondence: Herman Merte, Jr., Mechanical Engineering Dept., 2026 G.G. Brown Building, University of Michigan, Ann Arbor, MI 48109-2125, USA. Voice: 734-7645240; fax: 734-647-3170.

merte@umich.edu

Ann. N.Y. Acad. Sci. 1027: 196-216 (2004). (C2004 New York Academy of Sciences. doi: 10.1196/annals.1324.018 


\section{INTRODUCTION}

The relatively recent availability of long-term, high quality microgravity associated with space flight provides opportunities for the study of pool boiling under this condition, resulting in insights into its behavior not encountered in Earth gravity. As has been extensively and well demonstrated over the years, the phenomena of nucleate or bubble boiling, including both pool and flowing, are highly complex, resisting attempts to describe or predict their behavior under the variety of parameters to which they may be subjected in applications. Considerable progress has indeed been made in this regard and is expected to continue in light of the continuing advances in measurement and computational capabilities. However, it should be recognized that the lack of adequate understanding of the mechanisms involved severely inhibits the capacity for modeling, and therefore, for computation. Hence, the necessity, at times, for experiments that are accompanied and followed by analytical activities for purposes of confirmation.

Pool boiling experiments were conducted on five space shuttle flights as part of the NASA Get Away Special (GAS) program during the period 1992-1996. Detailed descriptions of the hardware, procedures and general results are given elsewhere. ${ }^{1,2}$ A brief description of certain unexpected behaviors encountered is repeated below for convenience, as well as a description of the hardware in the following section. The objective of this paper is to present some initial quantitative results for one of these unexpected behaviors obtained from measurements to date. Needless to say, were some of these unexpected behaviors "expected", the design of the experiments and the corresponding instrumentation might have been quite different.

Two identical facilities resulted from the development of the experiment, a prototype and a flight version. Each flight experiment consisted of three levels of input heat flux and three levels of initial liquid subcooling, for a total of nine different test runs per flight. The nominal variable parameters associated with each flight are given in TABLE 1. These were identical in the first three flights except for minor changes in timing of the camera speeds. These three flights are of special significance in that any questions as to the reproducibility of the unexpected behaviors are answered. The first and third are identical experiments with identical hardware; the first and second (or second and third) are identical experiments with different hardware of identical construction. For the fourth and fifth flights, an opportunity was taken to increase the levels of subcooling and to decrease the imposed input heat flux, respectively. Viewing the first three flights as one, one experiment in each flight employed the same

TABLE 1. Nominal variable parameters used for pool boiling experiments

\begin{tabular}{lccc}
\hline Shuttle Flight & $\begin{array}{c}\text { Initial Bulk Liquid } \\
\text { Subcooling }\left({ }^{\circ} \mathrm{C}\right)\end{array}$ & $\begin{array}{c}\text { Imposed Heat Flux to } \\
\text { Film Heater }\left(\mathrm{W} / \mathrm{cm}^{2}\right)\end{array}$ & Hardware \\
\hline STS-47 & $11.1,2.8,0.3$ & $8,4,2$ & prototype \\
STS-57 & $11.1,2.8,0.3$ & $8,4,2$ & flight \\
STS-60 & $11.1,2.8,0.3$ & $8,4,2$ & prototype \\
STS-72 & $22.2,16.7,11.1$ & $8,4,2$ & flight \\
STS-77 & $11.1,2.8,0.3$ & $2,1,0.5$ & flight \\
\hline
\end{tabular}


parameters as used in the third, fourth, and fifth flights in order to confirm reproducibility within the last two flights.

In 26 of the total of 45 experiments $(9 \times 5)$, conditions of what can be termed steady-state pool boiling were surprisingly achieved during the two minutes generally allocated for each experiment. In all of these boiling was associated with the formation, growth, and motion of relatively small vapor bubbles, giving rise to average heat transfer coefficients often greater than values obtained in Earth gravity, as presented elsewhere. ${ }^{3,4}$ In the remaining 19 of the 45 experiments, a continuous temperature rise of the heater surface occurred resulting from dryout. Dryout of the heater surface took place in all cases with the highest input heat flux of $q^{\prime \prime}=8 \mathrm{~W} / \mathrm{cm}^{2}$, except when the largest bulk liquid subcooling, $22.2^{\circ} \mathrm{C}$, was applied during the STS-72 flight. As described by Lee et al. ${ }^{4}$ highly effective steady-state boiling takes place when a large vapor bubble slightly removed from the heater surface is present to act as a reservoir for the small bubbles growing beneath, thereby inhibiting the onset of dryout. This behavior took place with a combination of moderate heat flux levels, 4 and $2 \mathrm{~W} / \mathrm{cm}^{2}$, and subcoolings below $16.7^{\circ} \mathrm{C}$ (TABLE 1). Increasing the subcooling to $22.2^{\circ} \mathrm{C}$ eliminated the formation of a large vapor bubble, but still produced highly effective steady boiling because of thermocapillary effects, ${ }^{5}$ with a technical basis presented most recently by Betz and Straub $^{6}$ and by Sides. ${ }^{7}$

According to the theories of thermocapillarity, the large vapor bubble described above, which acts as a reservoir to produce steady-state boiling, should be impelled toward the heated surface, resulting in dryout and unsteady behavior. The mechanistic elements that are believed to inhibit this are presented in the following sections, together with order-of-magnitude estimates of the forces involved, as determined from the space experiments.

A description of two additional interesting and unexpected behaviors arising with pool boiling in microgravity are briefly repeated here. The first is what is termed quasihomogeneous nucleation, in which slow heating produces nucleation that appears not to take place on the heating surface itself. For all experiments with input heat flux levels of $q^{\prime \prime}=4 \mathrm{~W} / \mathrm{cm}^{2}$ and below shown in TABLE 1 (a total of 33 of the 45 experiments), initial nucleation occurred at various and apparently random locations over the heating surface, and thus could not be identified with a geometric characteristic of the surface itself. The theoretical basis for the influence of system pressure, used to produce the bulk liquid subcooling, and these low levels of heat flux, were accounted for by a modification of classical homogenous nucleation theory, with the details presented elsewhere. ${ }^{8}$ What remains to be done to remove the quasi term from the title above is a definitive observation of nucleation indeed taking place away from the heater surface. For the remaining 12 (of 45) experiments in TABLE 1 conducted with an input heat flux of $q^{\prime \prime}=8 \mathrm{~W} / \mathrm{cm}^{2}$, nucleation invariably took place at the same physical location on the heater surface, differing only between the two sets of hardware used, and thus was characterized as heterogeneous nucleation. A physical (and theoretical) explanation for the role of the input heat flux in producing these two different (apparently) types of nucleation in microgravity remains to be determined.

The second unexpected behavior here is the extremely dynamic or "explosive" type of vapor bubble growth at low levels of heat flux, generally following the quasihomogeneous nucleation described above. The standard macroscopic conservation 
and transport equations successfully describe the vapor bubble growth rates associated with heterogeneous nucleation. ${ }^{9,10}$ Dynamic vapor bubble growth, on the other hand, is characterized by liquid-vapor interfaces that are wrinkled and corrugated, leading to the conclusion that some type of instability mechanism is acting. A theoretical basis for this is given elsewhere, ${ }^{11}$ although the dynamics of vapor bubble growth under these conditions remain to be modeled.

\section{DESCRIPTION OF EXPERIMENTAL HARDWARE}

As can be seen in FIGURES 1 and 2, two heater surfaces are placed on a single flat substrate, with one acting as a backup, installed so as to form one wall of the test vessel having internal dimensions $15.2 \mathrm{~cm}$ diameter by $10.2 \mathrm{~cm}$ height.

Each heater consists of a $400 \AA$ thick semitransparent gold film sputtered on a highly polished quartz substrate, and serves simultaneously as a heater, with an uncertainty of $\pm 2 \%$ in the heat flux, and a resistance thermometer, with an overall uncertainty of $\pm 1.0^{\circ} \mathrm{C}$ in the mean surface temperature. The heater is rectangular, $19.05 \times 38.1 \mathrm{~mm}(0.75 \times 1.5 \mathrm{inch})$. System subcooling is obtained by increasing the system pressure above the saturation pressure and is controlled and measured with an uncertainty of $\pm 0.345 \mathrm{kPa}$. Degassed commercial grade R-113 was used because of its electrical nonconductivity, compatible for direct contact with the thin gold film heater.

In light of the propensity for the R-113 to absorb large amounts of gases, considerable efforts were expended to reduce the dissolved gases to the lowest practical level, thereby minimizing the possibility for thermocapillary convection around bubbles

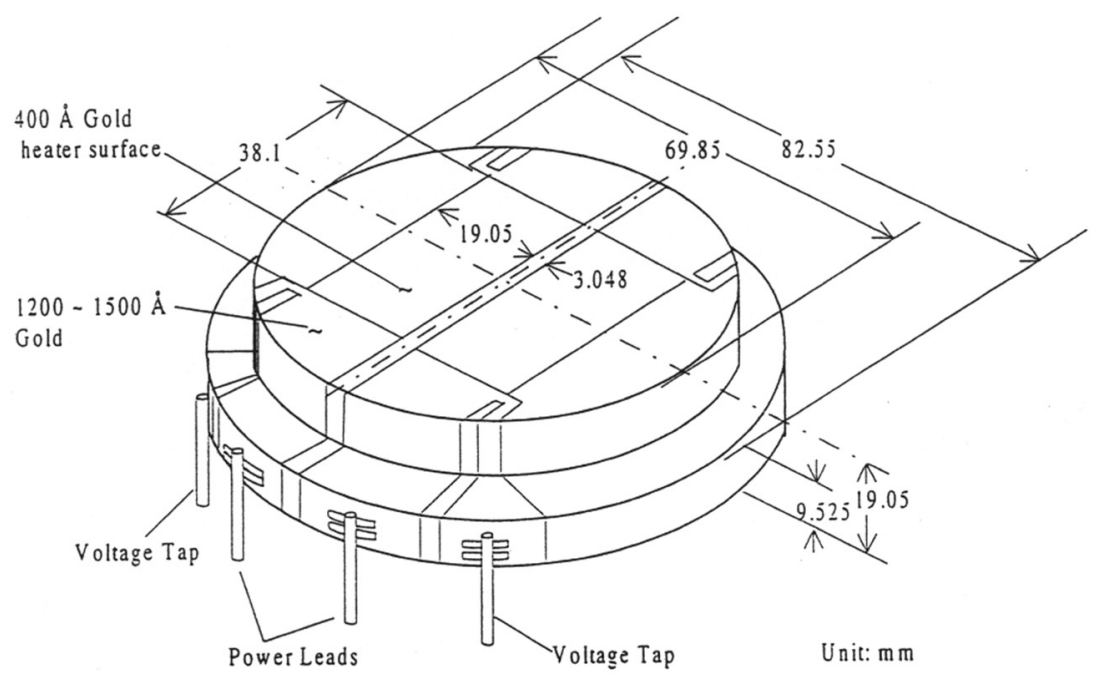

FIGURE 1. Transparent gold film heater/resistance thermometer on quartz substrate. 


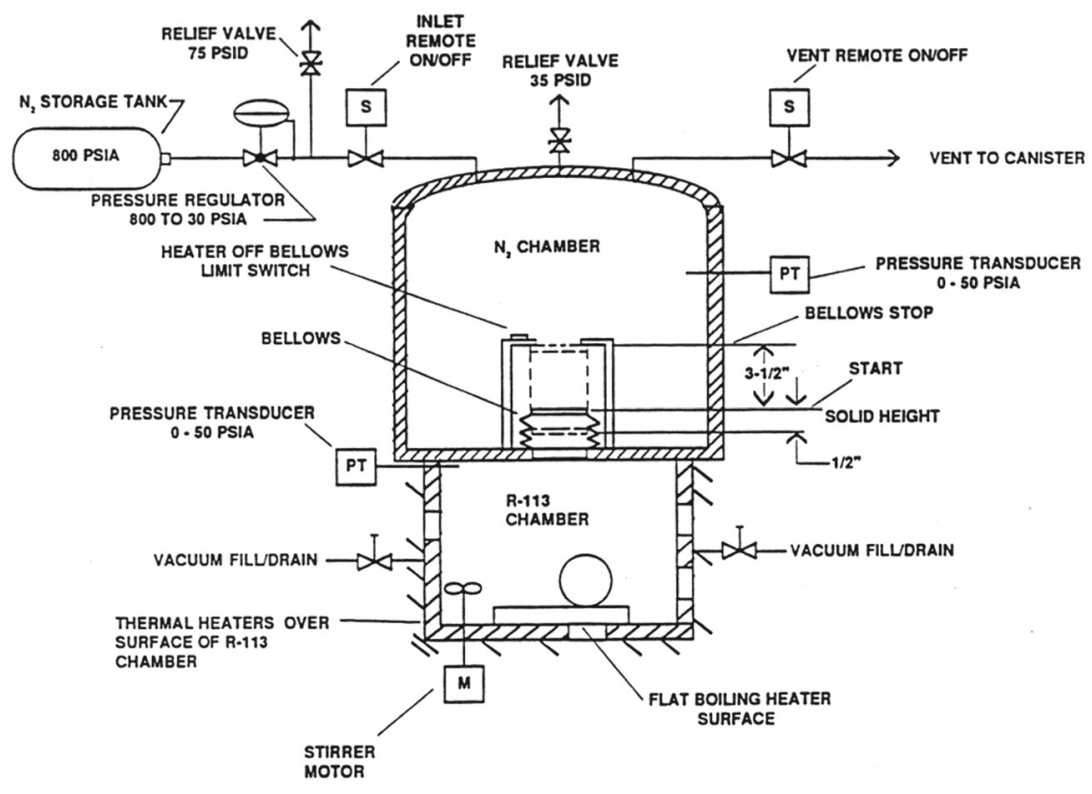

FIGURE 2. Schematic of test vessel.

containing mixtures of gas and vapor. ${ }^{6}$ The R-113 was purified and degassed by a double distillation process, a molecular sieve and freezing on a highly convoluted surface at liquid nitrogen temperature levels, while continuously pumping out at a low pressure. The degassing was deemed adequate when the measured vapor pressure conformed to the equation of Mastroianni et al., ${ }^{12}$ to within the accuracy of the standard laboratory instruments $\left( \pm 0.06^{\circ} \mathrm{C}\right.$ and $\left.\pm 170 \mathrm{~Pa}\right)$ over the temperature range used.

Photographs of the boiling process were obtained simultaneously from the side and from beneath the heater surface at framing rates of 10 and $100 \mathrm{fps}$, with a $16-\mathrm{mm}$ cine camera. An example is given in FigurE 3.

\begin{abstract}
ANALYSIS
FIGURE 4 is a schematic of the representative photograph in FIGURE 3 in which a relatively large vapor bubble is maintained off of the heater surface, in opposition to the thermocapillary forces that otherwise would move this bubble toward the heated surface, producing dryout as described in the previous section. This opposing force is ascribed to the momentum of small bubbles nucleating and growing beneath large bubbles, arising from the conversion of surface energy to kinetic energy as the small bubbles combine with the large one. Holding the large bubbles away from the heater surface permits liquid inflow beneath, producing the resulting steady nucleate boiling observed.
\end{abstract}




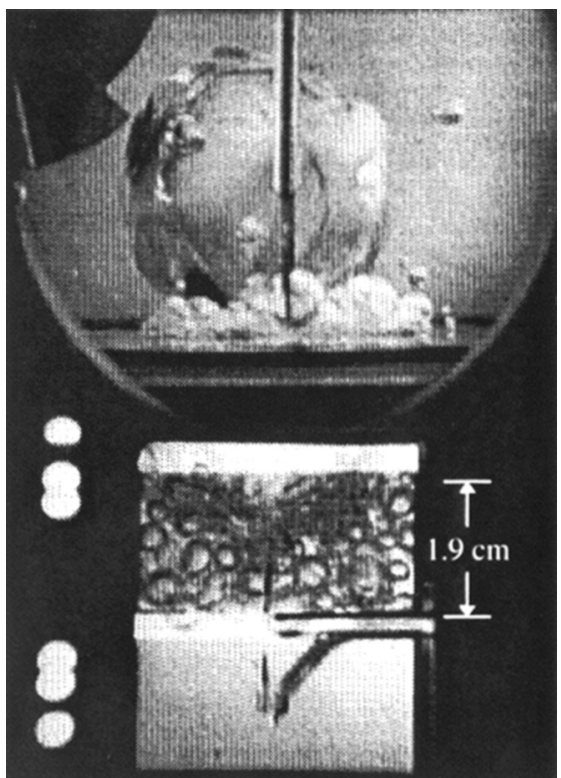

FIGURE 3. Representative photograph of steady nucleate pool boiling in microgravity: STS-60 Run \#2; $q^{\prime \prime}=4 \mathrm{~W} / \mathrm{cm}^{2}, \Delta T_{\text {sub }}=11.1^{\circ} \mathrm{C}$; frame \#1329; time, $51.23 \mathrm{sec}$.

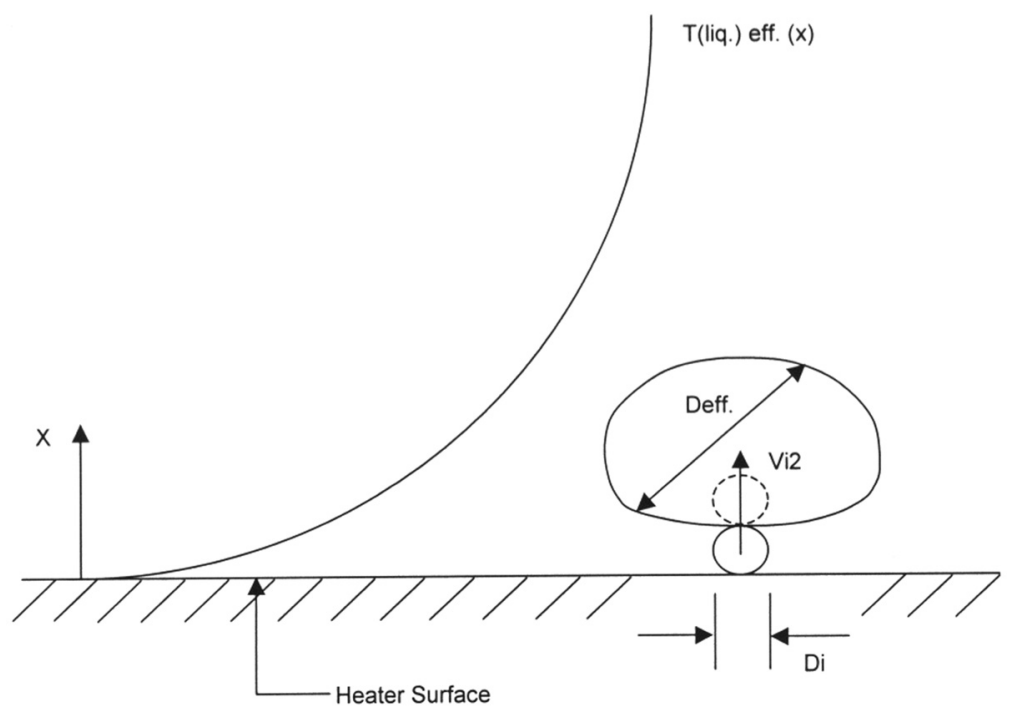

FIGURE 4. Model for sustaining a large vapor bubble away from heater surface in microgravity to counter thermocapillarity. 
From measurements of the size of the small bubbles as they combine with the larger ones, and the frequency of this process, it is possible to estimate the order of magnitude of the forces involved, which at some future time might be compared with estimates of the associated thermocapillary forces.

For a vapor bubble of diameter $D_{i}$ at the moment of combination with a large bubble, at which point it "disappears" from the field of view, the surface energy per bubble is given by

$$
E_{i}=\sigma_{i} \pi D_{i}^{2}
$$

Assuming that this energy is converted completely (ideally) to kinetic energy when the two bubbles combine, then

$$
K E_{i}=\frac{1}{2} m_{b_{i}} V_{i}^{2}=\frac{1}{2}\left(\rho_{v i} \times \frac{1}{6} \pi D_{i}^{3}\right) V_{i}^{2}=\sigma_{i} \times \pi D_{i}^{2}
$$

or

$$
V_{i}^{2}=\frac{12 \sigma_{i}}{\rho_{v_{i}} D_{i}} \equiv \bar{V}_{i}^{2}
$$

The force contribution from bubbles of size $i$, neglecting any initial velocity, is

$$
F_{i}=\frac{d}{d t}\left(m_{i} V_{i}\right)=\dot{m}_{i} \bar{V}_{i}
$$

The total force for all bubble sizes is

$$
F_{i}=\sum_{i=1}^{n_{t}} F_{i}=\sum_{i=1}^{n_{t}} \dot{m}_{i} \bar{V}_{i},
$$

where $n_{i}$ is the total number of bubble sizes considered. The mass flow rate of bubbles of size $D_{i}$ is

$$
\dot{m}_{i}=\bar{f}_{i} \times(\text { mass/bubble })=\bar{f}_{i} \times\left(\rho_{v_{i}} \times \frac{\pi D_{i}^{3}}{6}\right),
$$

where $\bar{f}_{i}$ is the mean bubble frequency of size $i$. Substituting Equations (3) and (6) into (5),

$$
F_{i}=\pi \sum_{i=1}^{n_{t}} \bar{f}_{i} \times\left(\frac{\sigma_{i} \times \rho_{v_{i}}}{3}\right)^{1 / 2} \times D_{i}^{5 / 2} .
$$

It was noted that the vapor bubble generation rate at any particular physical location on the heater surface was never faster than the film framing rate used here, 10pps, which means that all "disappearing" bubbles of size $D_{i}$ could be observed and counted with reasonable certainty. That the bubble generation rate is this low in microgravity appears reasonable, since these bubbles are between the large sink bubble and the heating surface, where the liquid is unlikely to be significantly subcooled. This was confirmed by liquid thermistor temperature measurements $1 \mathrm{~mm}$ above the center of the heater.

It was found to be adequate to count the disappearing bubbles within only four size ranges $i$ in each frame, with diameters between $2-4 \mathrm{~mm}, 4-6 \mathrm{~mm}, 6-8 \mathrm{~mm}$, and $8-10 \mathrm{~mm}$ and then use the mean diameter within each of these ranges in Equation (7). The mean frequencies of each of these four size ranges were determined by 
averaging each over \pm 1 second ( \pm 10 frames) for each time of interest, and then advancing one frame at a time over the entire period of interest. Computation of the time-varying forces induced by the disappearing bubbles on the large hovering bubbles were then carried out using (7).

\section{RESULTS}

The variation of the mean heater surface temperature and the derived heat transfer coefficient are shown in FIGURE 5 for the entire experiment period of two minutes for STS-47 Run \# 9. This plot is taken directly from Merte et al. ${ }^{1}$ Following the steady nucleate boiling up to 80 seconds the large vapor bubble resulting from the virtually saturated liquid condition contacted the opposite side of the test vessel, producing the subsequent dryout and associated heater surface temperature rise.

The lift-off force induced by the disappearing or engulfed bubbles, computed from (7), is shown in FIGURE 6 for the steady 70-80 second time interval. Note that this varies over approximately 3.8-5.6N, which can be considered essentially constant if some smoothing of the small-scale oscillations takes place.

The frequencies of the engulfed bubbles corresponding to the four size ranges measured are plotted in FIGURE 7. On comparing the force contributions of each of these size ranges to the total shown in FIGURE 6, it becomes obvious that the major contributions come from bubbles in the two smaller size ranges, $2-4 \mathrm{~mm}$ and 4-6 mm. This was also true for the majority of the additional experiments whose bubble measurements have been completed, and for which only the results corresponding to FIGURES 5 and 6 are given below.

The four pairs of FIGURES 5 and 6,8 and 9, 10 and 11, and 12 and 13, all have the same input level of heat flux, with the latter three differing from that of FIGURES 5 and 6 in having a higher subcooling level of $3^{\circ} \mathrm{C}$ (vice $0.3^{\circ} \mathrm{C}$ ). We restate here that in comparing the resulting behaviors and their differences, FIGURES 5, 8, and 12 and the corresponding FIGURES 6, 9, and 13 were obtained with the prototype experimental hardware, whereas FIGURES 10 and 11 were obtained with the identically

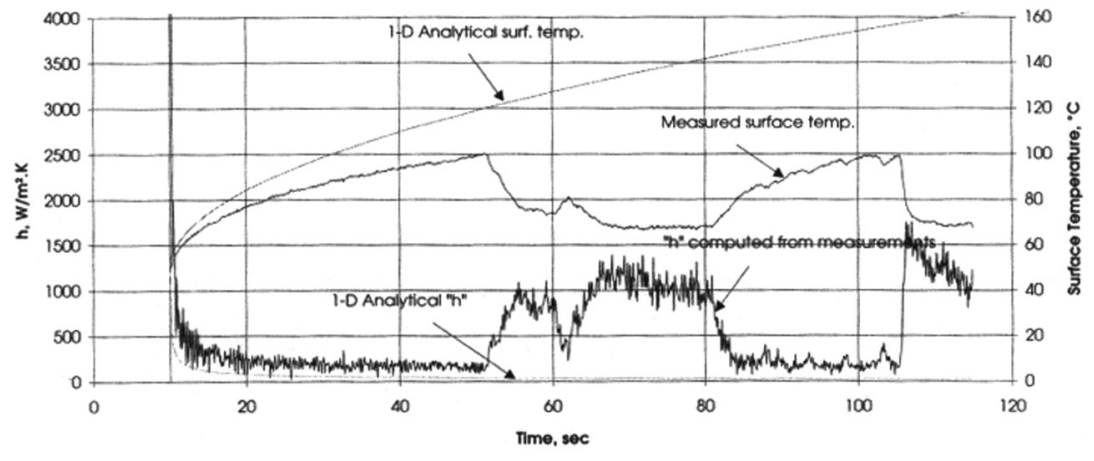

FIGURE 5. Mean heater surface temperature and heat transfer coefficient: STS-47 Run \#9, $q^{\prime \prime}=2 \mathrm{~W} / \mathrm{cm}^{2}, \Delta T_{\text {sub }}=0.3^{\circ} \mathrm{C}$. 


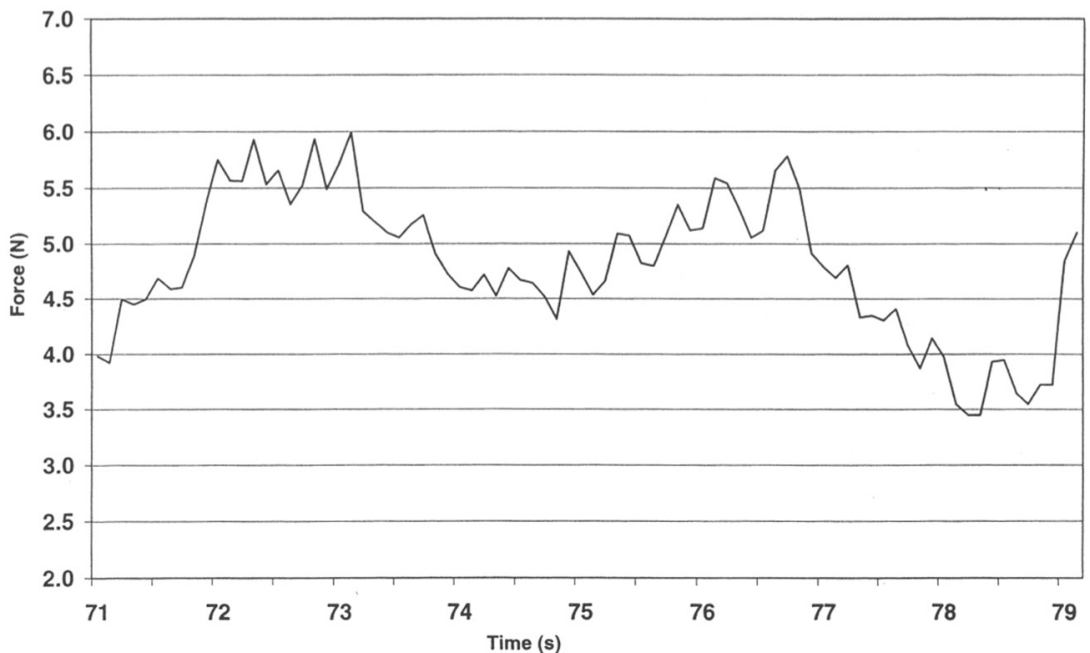

FIGURE 6. Lift-off force induced by engulfed bubbles: STS-47 Run $\# 9, q^{\prime \prime}=2 \mathrm{~W} / \mathrm{cm}^{2}$, $\Delta T_{\text {sub }}=0.3^{\circ} \mathrm{C}$.

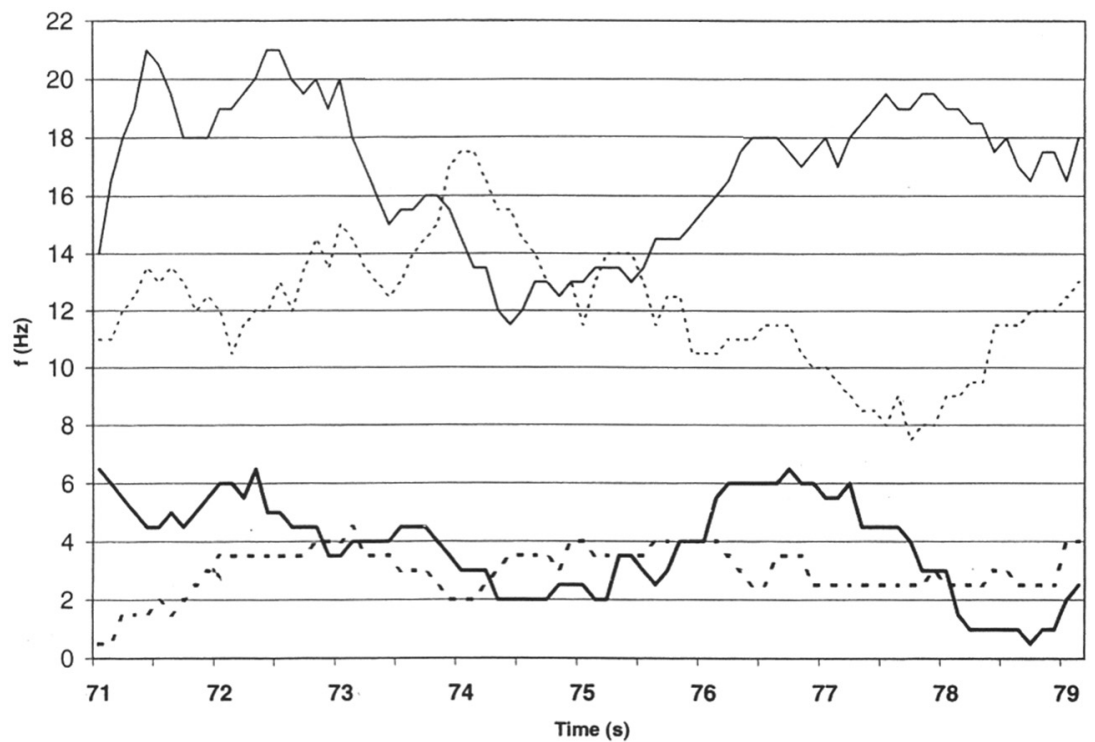

FIGURE 7. Frequency of the engulfed bubbles in FIGURE 6 for the four size ranges measured: - $-2-4 \mathrm{~mm} ; \cdots \cdots, 4-6 \mathrm{~mm} ;-, 6-8 \mathrm{~mm} ; \cdots,-\cdot 10 \mathrm{~mm}$; STS-47 Run \#9. 


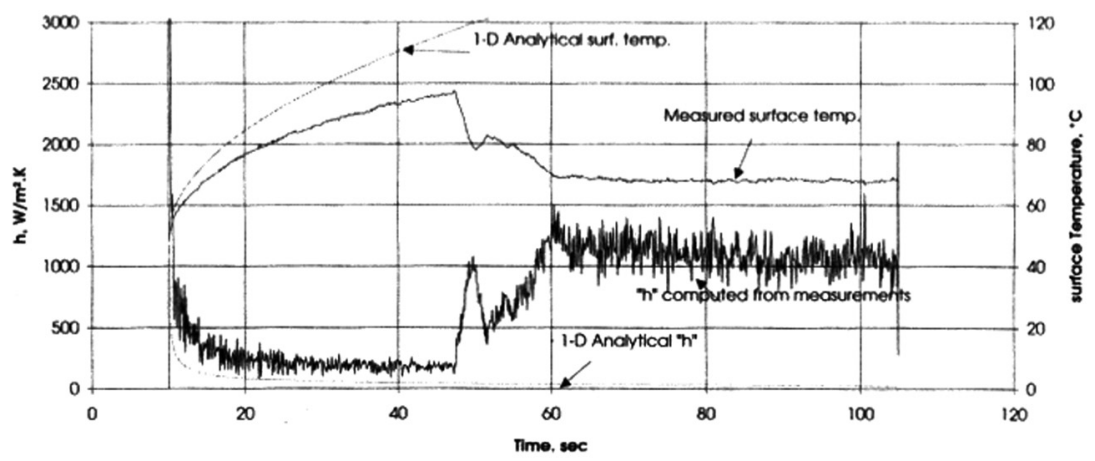

FIGURE 8. Mean heater surface temperature and heat transfer coefficient: STS-47 Run \#6, $q^{\prime \prime}=2 \mathrm{~W} / \mathrm{cm}^{2}, \Delta T_{\text {sub }}=3^{\circ} \mathrm{C}$.

designed flight experimental hardware. Thus, on comparing FIGURES 8 and 9 with the corresponding FIGURES 12 and 13, the reproducibility is excellent for the initial nucleation heater surface temperature (and the related time to the onset of nucleation), the subsequent steady heater surface temperature, and the derived mean heat transfer coefficient. Comparisons between the liftoff forces, varying over 4.0-1.8 N in FIGURE 9 and 2.5-0.8 $\mathrm{N}$ in FIGURE 13 suggest that they are reasonably reproducible, when viewing the dynamic and somewhat chaotic motions of the larger hovering bubbles.

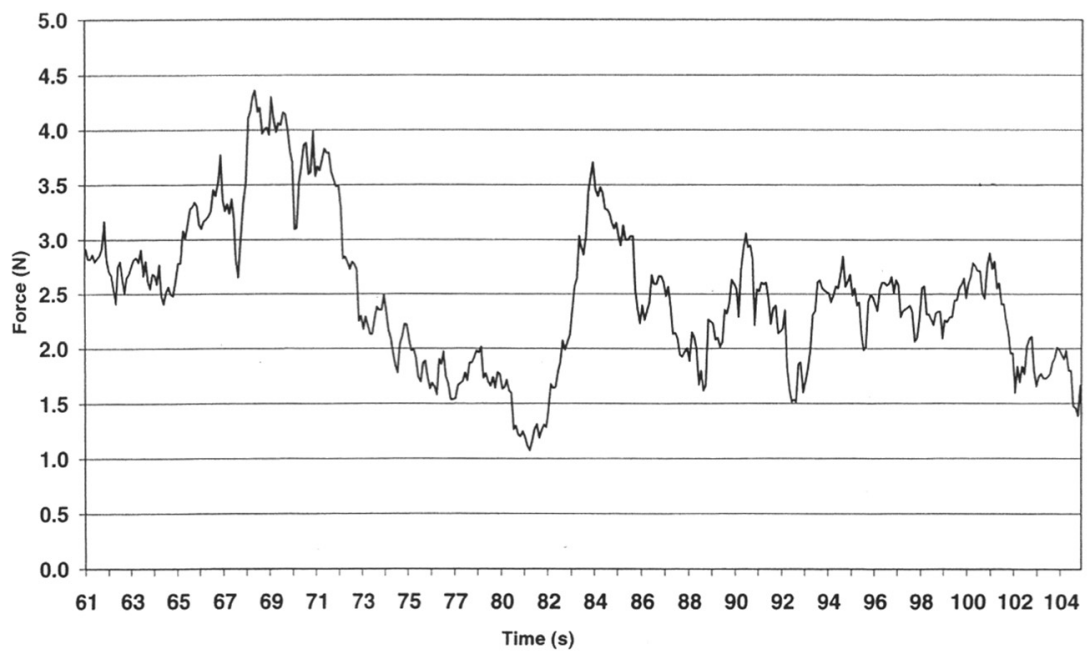

FIGURE 9. Liftoff force induced by engulfed bubbles: STS-47 Run \#6, $q^{\prime \prime}=2 \mathrm{~W} / \mathrm{cm}^{2}$, $\Delta T_{\text {sub }}=3^{\circ} \mathrm{C}$. 


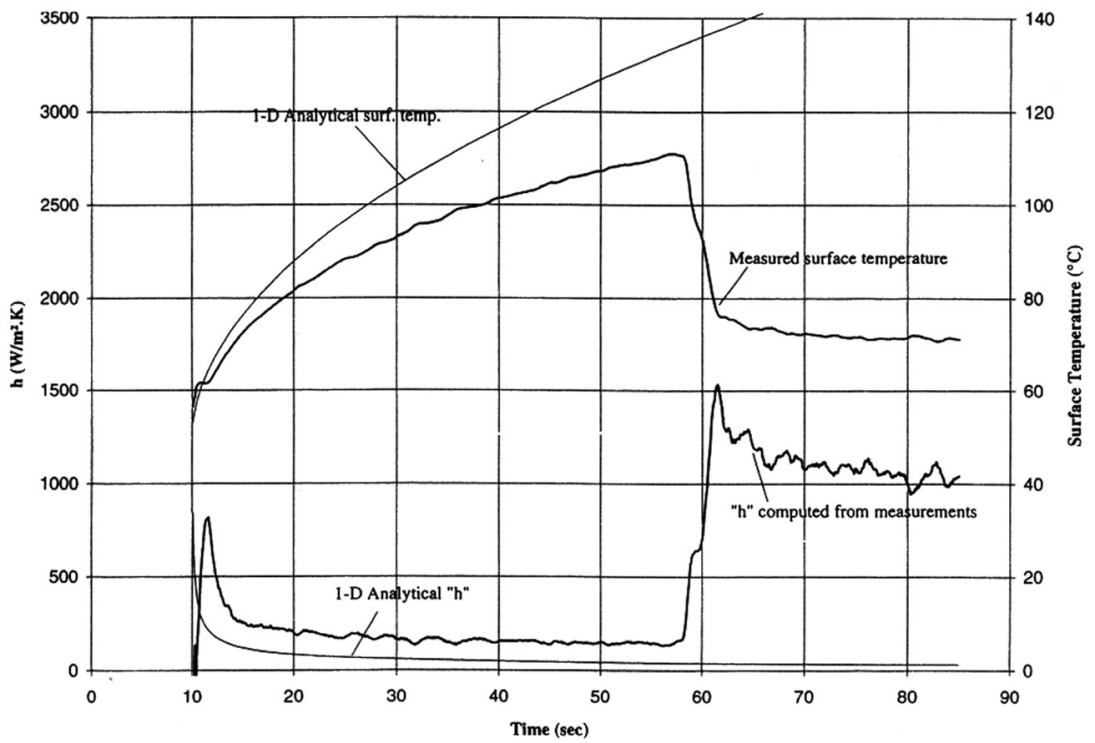

FIGURE 10. Mean heater surface temperature and heat transfer coefficient: STS-57 Run \#6, $q^{\prime \prime}=2 \mathrm{~W} / \mathrm{cm}^{2}, \Delta T_{\text {sub }}=3^{\circ} \mathrm{C}$.

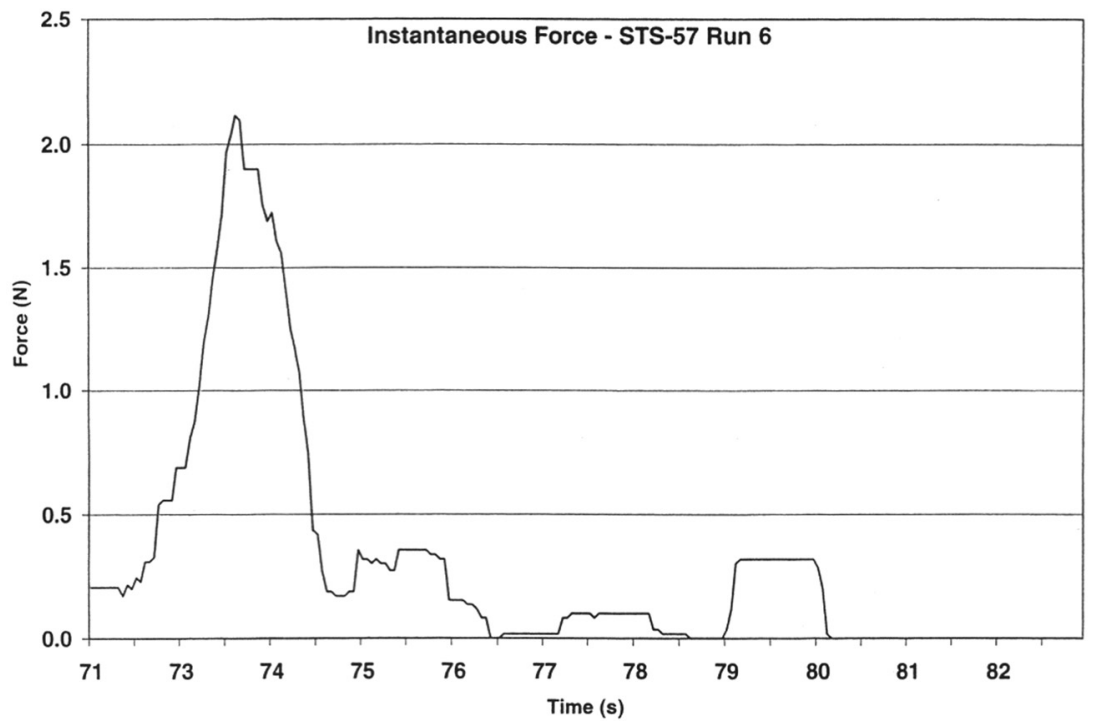

FIGURE 11. Lift-off force induced by engulfed bubbles: STS-57 Run \#6, $q^{\prime \prime}=2 \mathrm{~W} / \mathrm{cm}^{2}$, $\Delta T_{\text {sub }}=3^{\circ} \mathrm{C}$. 


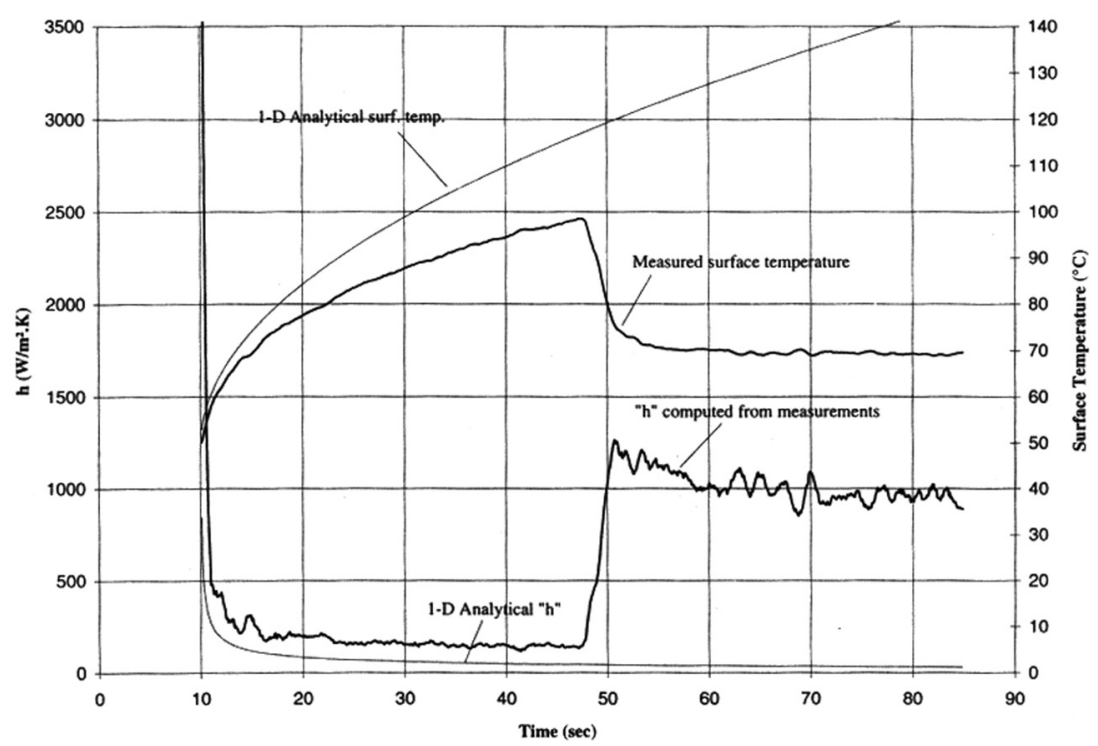

FIGURE 12. Mean heater surface temperature and heat transfer coefficient: STS-60 Run \#6, $q^{\prime \prime}=2 \mathrm{~W} / \mathrm{cm}^{2}, \Delta T_{\text {sub }}=3^{\circ} \mathrm{C}$.

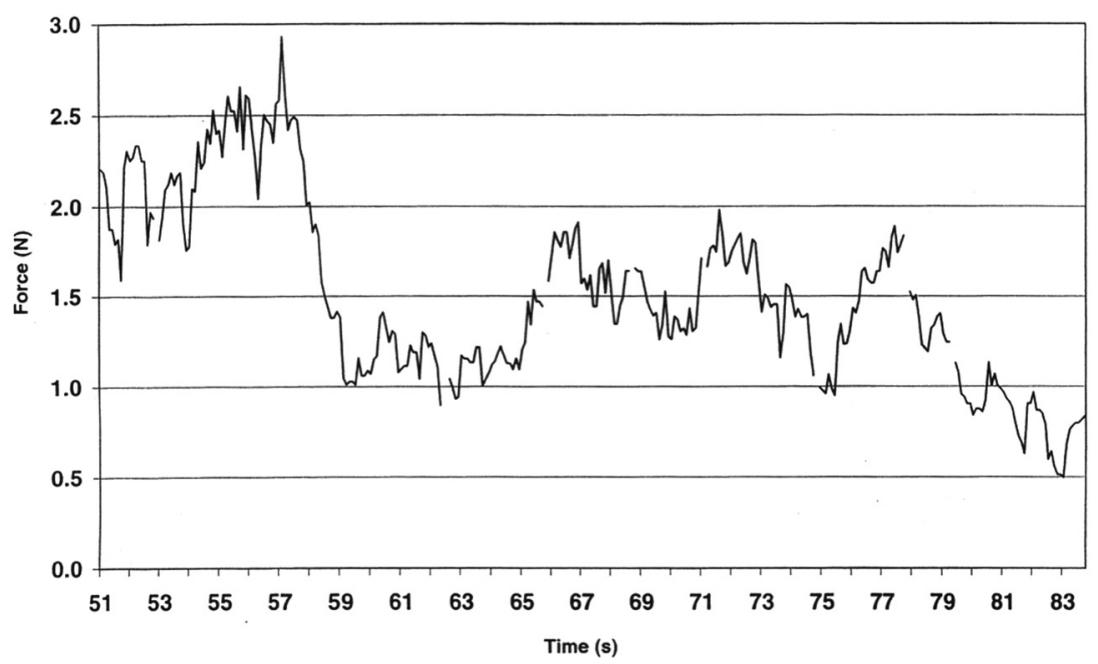

FIGURE 13. Lift-off force induced by engulfed bubbles: STS-60 Run \#6, $q^{\prime \prime}=2 \mathrm{~W} / \mathrm{cm}^{2}$, $\Delta T_{\text {sub }}=3^{\circ} \mathrm{C}$. 
This is to be contrasted with the larger variability in FIGURE 11, with the flight hardware. This difference is associated with the longer time to nucleation in FIGURE 10 and the corresponding higher heater surface superheat at nucleation. This leads to a much more dynamic initial vapor bubble growth which, when combined with the resulting shorter experiment time remaining, is felt to require a longer time period for the violent interfacial instabilities to be dissipated.

As stated already, the variable parameters in the five space shuttle flights consisted of the imposed heater heat flux and the initial bulk liquid subcooling. It is instructive to examine the influence of these on the lift-off forces induced by the engulfed bubbles.

FIGURE 14 presents the mean heater surface temperature and heat transfer coefficient and FIGURE 15 shows the lift-off forces induced by the engulfed bubbles for STS-72 Run \#1, with an imposed heat flux $q^{\prime \prime}=8 \mathrm{~W} / \mathrm{cm}^{2}$ and initial subcooling $\Delta T_{\text {sub }}=22.2^{\circ} \mathrm{C}$. This is the only experiment among the 15 conducted at this highest heat flux level that produced a large hovering vapor bubble during the allotted experiment time. Because of the high initial liquid subcooling here, it took a considerable period of time for a large vapor bubble to become stable, until the subcooling around this bubble in the vicinity of the heater surface had decreased sufficiently because of condensation. Prior to this, highly subcooled nucleate boiling with small bubbles took place in the immediate vicinity of the heater surface. Of course, with a sufficiently long experimental time available it can be expected that condensation will reduce the bulk liquid subcooling, and the behavior would revert to that observed for lower subcooling levels, to be shown in the following figures. This would occur provided that dryout did not take place, which requires that the vessel be large enough

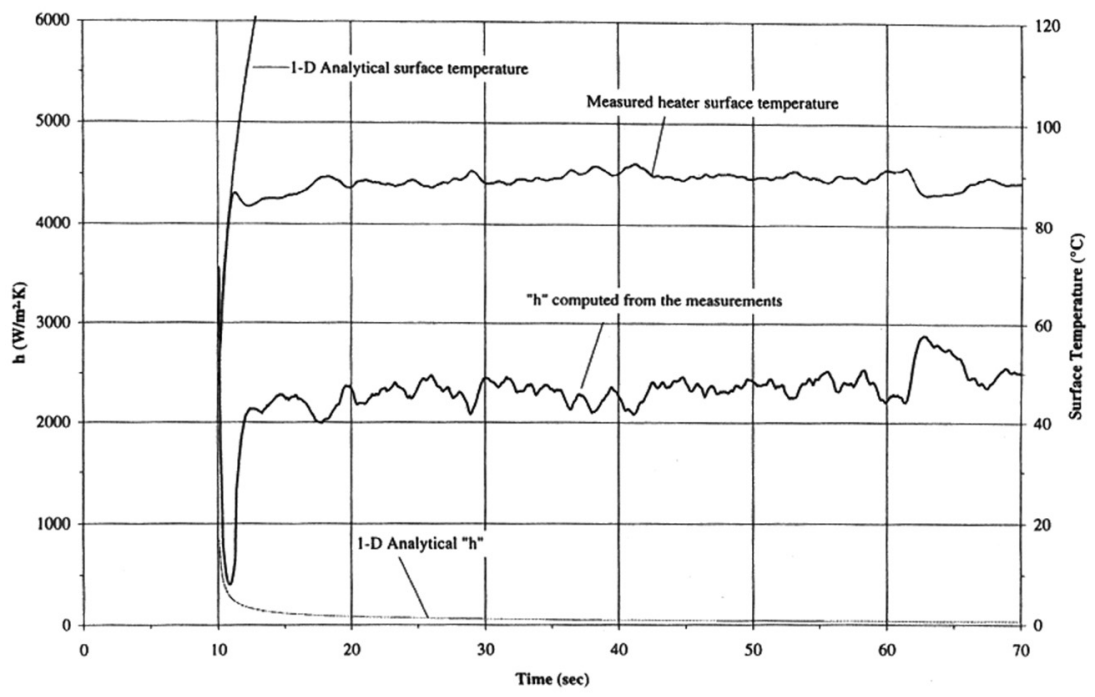

FIGURE 14. Mean heater surface temperature and heat transfer coefficient: STS-72 Run $\# 1, q^{\prime \prime}=8 \mathrm{~W} / \mathrm{cm}^{2}, \Delta T_{\text {sub }}=22.2^{\circ} \mathrm{C}$. 


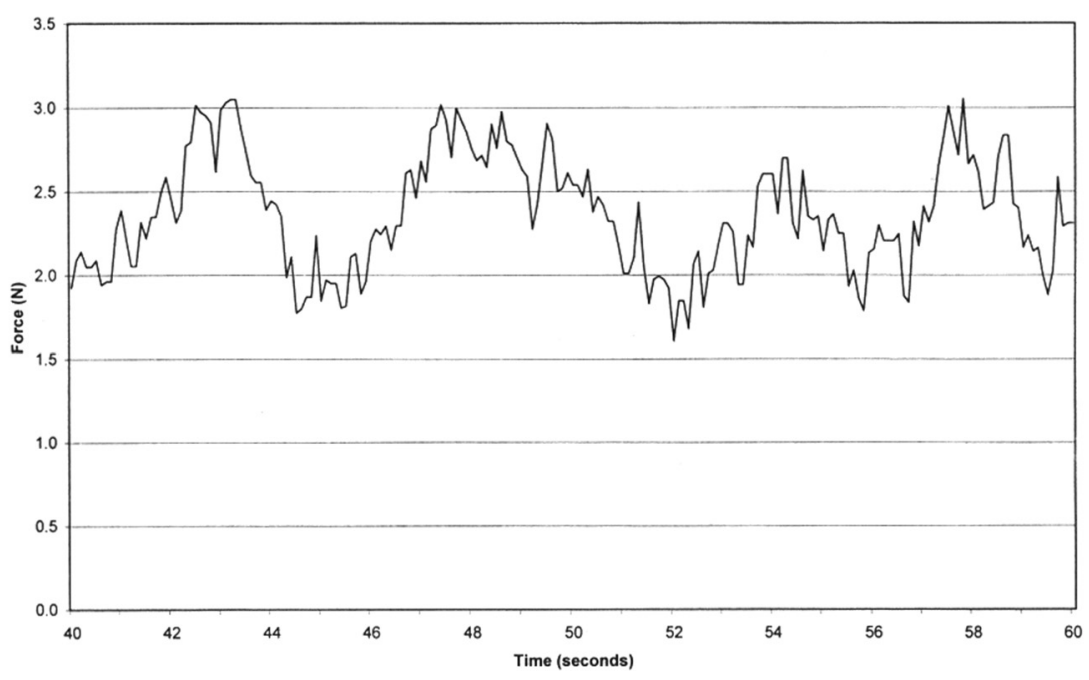

FIGURE 15. Liftoff force induced by engulfed bubbles: STS-72 Run $\# 1, q^{\prime \prime}=8 \mathrm{~W} / \mathrm{cm}^{2}$, $\Delta T_{\text {sub }}=22.2^{\circ} \mathrm{C}$.

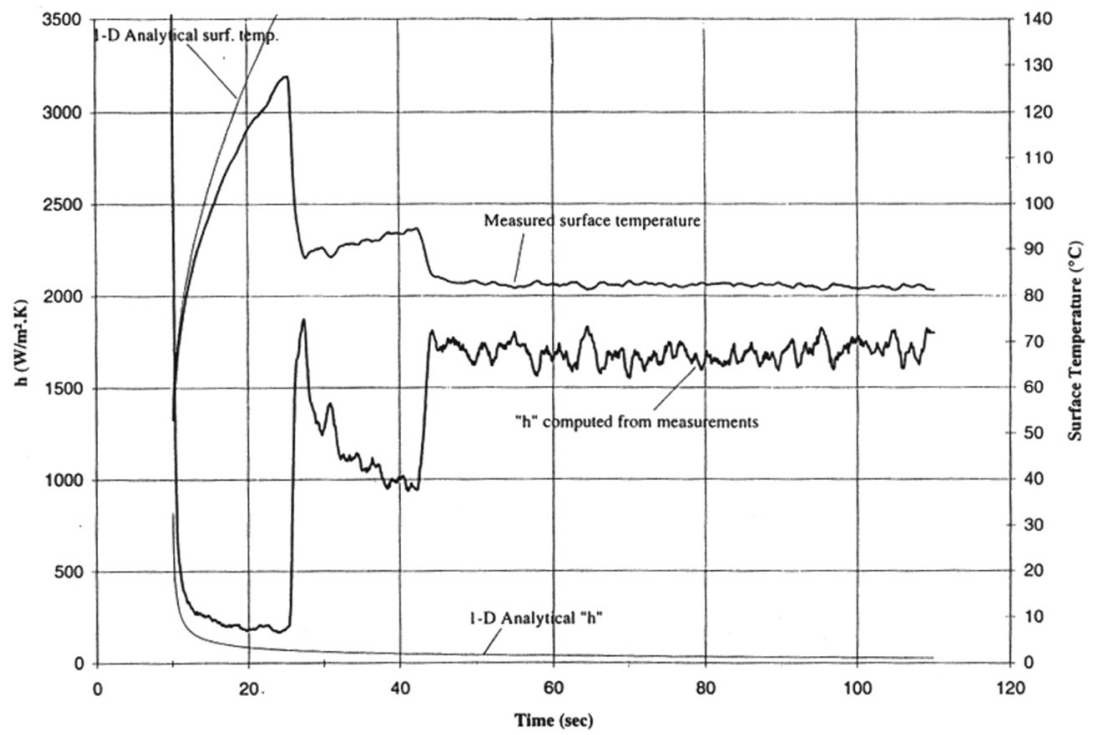

FIGURE 16. Mean heater surface temperature and heat transfer coefficient: STS-57 Run $\# 2, q^{\prime \prime}=4 \mathrm{~W} / \mathrm{cm}^{2}, \Delta T_{\text {sub }}=11.1^{\circ} \mathrm{C}$. 


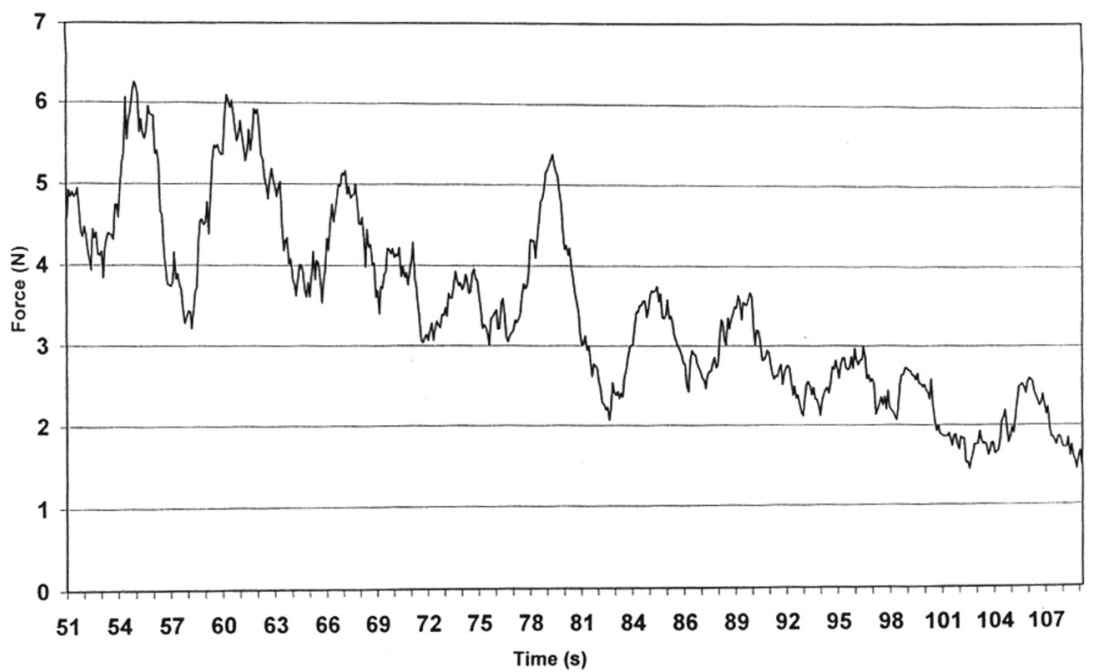

FIGURE 17. Liftoff force induced by engulfed bubbles: STS-57 Run \#2, $q^{\prime \prime}=4 \mathrm{~W} / \mathrm{cm}^{2}$, $\Delta T_{\text {sub }}=11.1^{\circ} \mathrm{C}$.

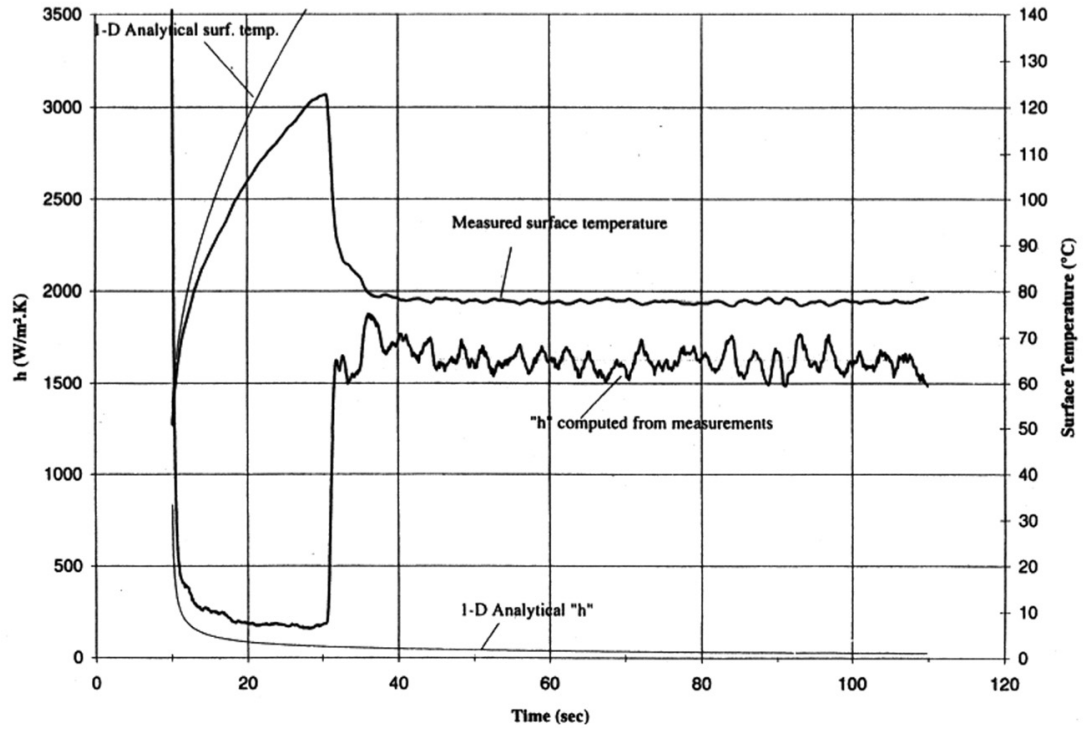

FIGURE 18. Mean heater surface temperature and heat transfer coefficient: STS-60 Run $\# 2, q^{\prime \prime}=2 \mathrm{~W} / \mathrm{cm}^{2}, \Delta T_{\text {sub }}=11.1^{\circ} \mathrm{C}$. 


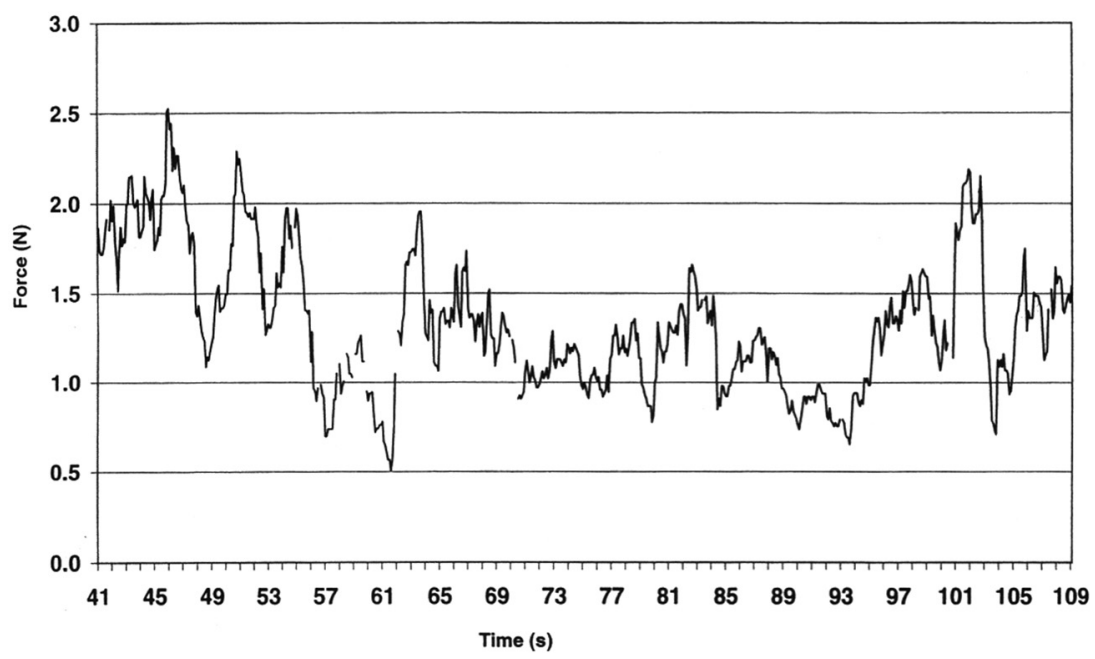

FIGURE 19. Liftoff force induced by engulfed bubbles: STS-60 Run $\# 2, q^{\prime \prime}=4 \mathrm{~W} / \mathrm{cm}^{2}$, $\Delta T_{\text {sub }}=11.1^{\circ} \mathrm{C}$.

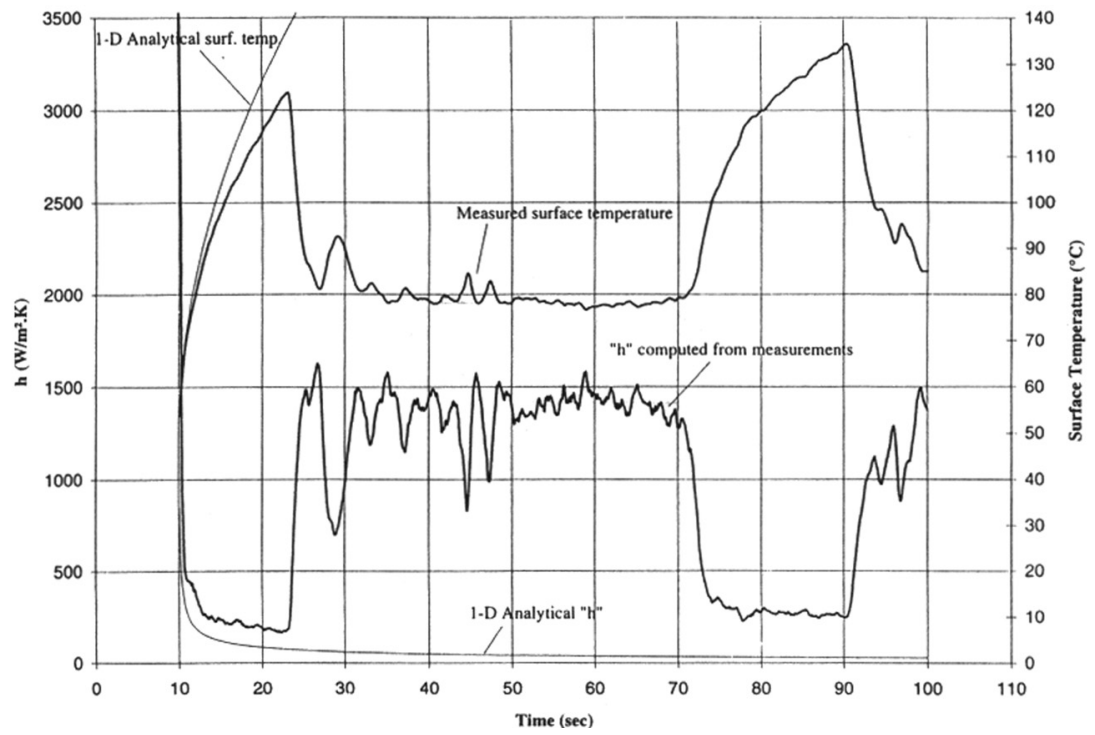

FIGURE 20. Mean heater surface temperature and heat transfer coefficient: STS-57 Run $\# 5, q^{\prime \prime}=4 \mathrm{~W} / \mathrm{cm}^{2}, \Delta T_{\text {sub }}=3^{\circ} \mathrm{C}$. 


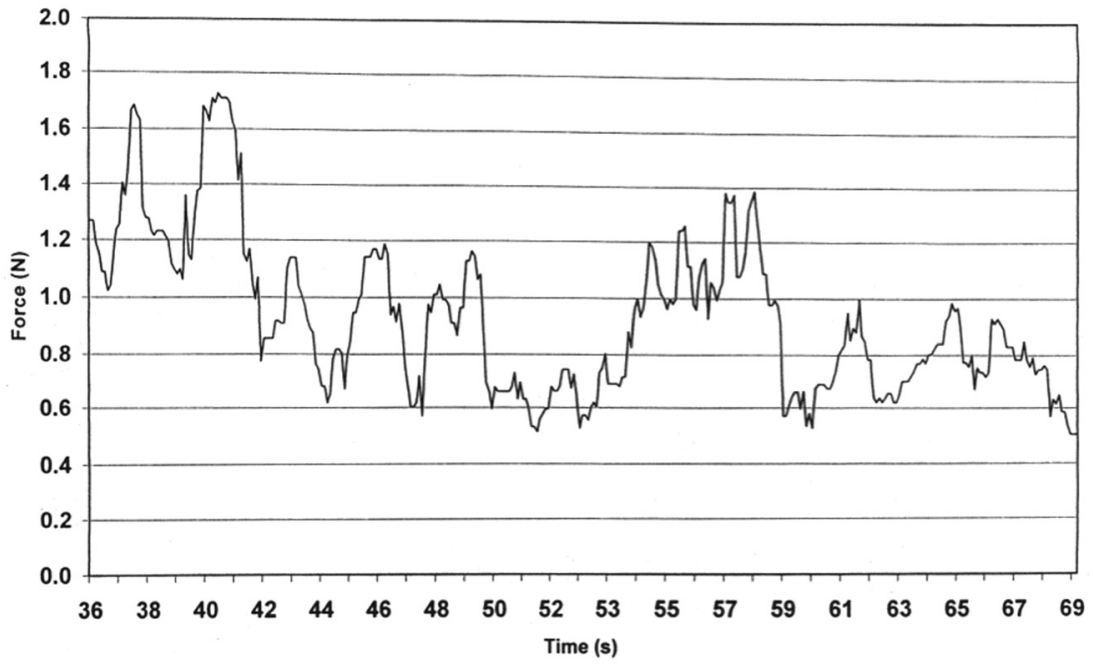

FIGURE 21. Liftoff force induced by engulfed bubbles: STS-57 Run \#5, $q^{\prime \prime}=4 \mathrm{~W} / \mathrm{cm}^{2}$, $\Delta T_{\text {sub }}=3^{\circ} \mathrm{C}$.

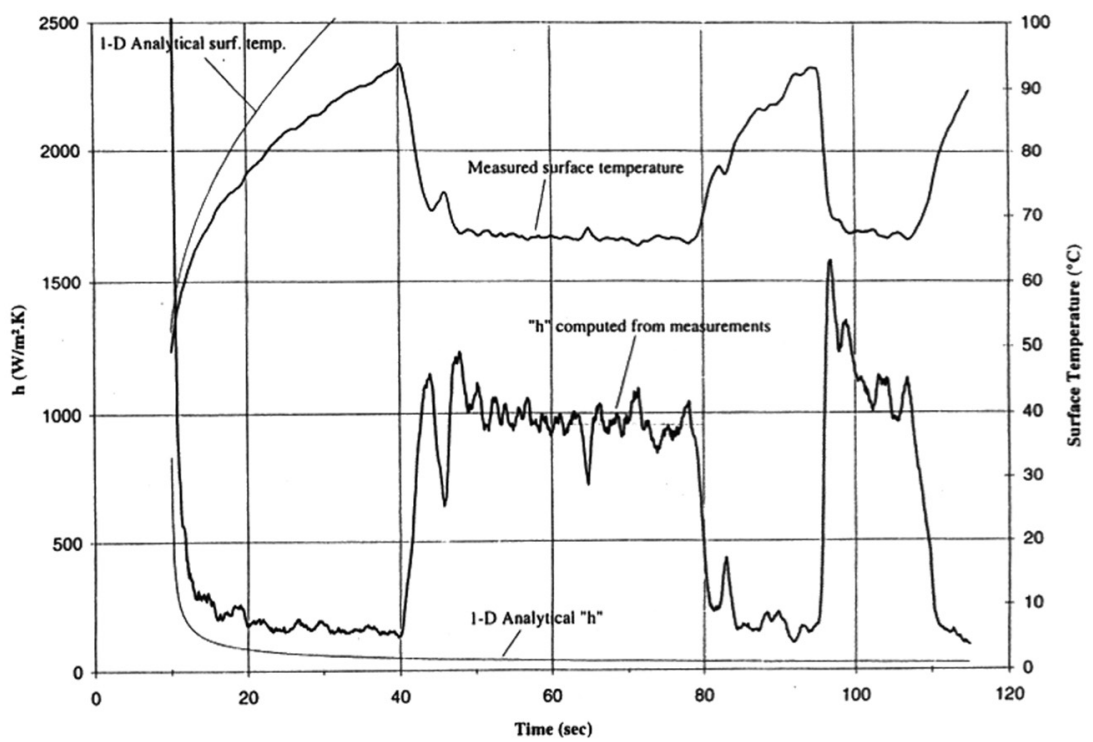

FIGURE 22. Mean heater surface temperature and heat transfer coefficient: STS-60 Run $\# 9, q^{\prime \prime}=2 \mathrm{~W} / \mathrm{cm}^{2}, \Delta T_{\text {sub }}=0.3^{\circ} \mathrm{C}$. 


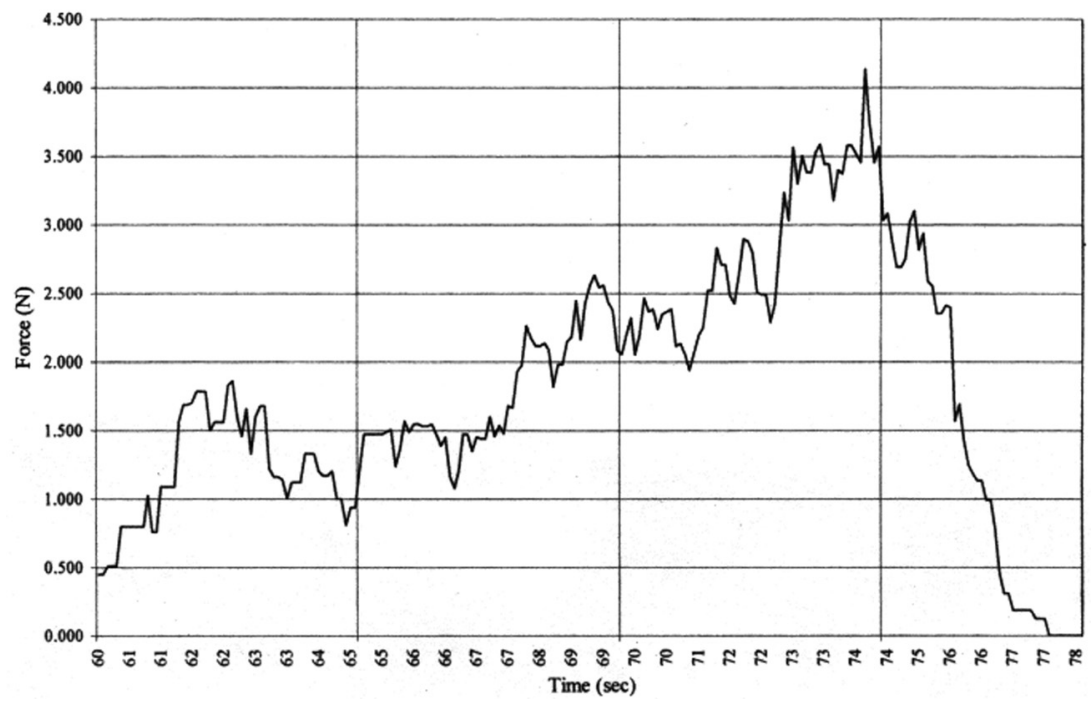

FIGURE 23. Liftoff force induced by engulfed bubbles: STS-60 Run $\# 9, q^{\prime \prime}=2 \mathrm{~W} / \mathrm{cm}^{2}$, $\Delta T_{\text {sub }}=0.3^{\circ} \mathrm{C}$.

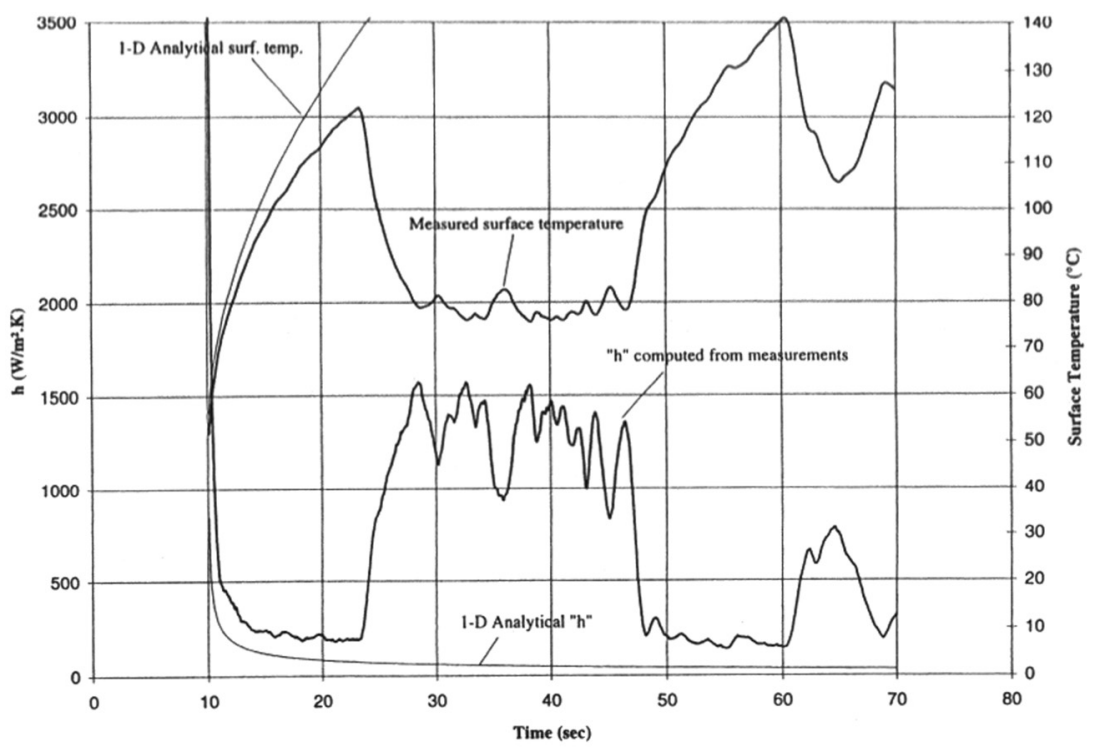

FIGURE 24. Mean heater surface temperature and heat transfer coefficient: STS-57 Run $\# 8, q^{\prime \prime}=4 \mathrm{~W} / \mathrm{cm}^{2}, \Delta T_{\text {sub }}=0.3^{\circ} \mathrm{C}$. 


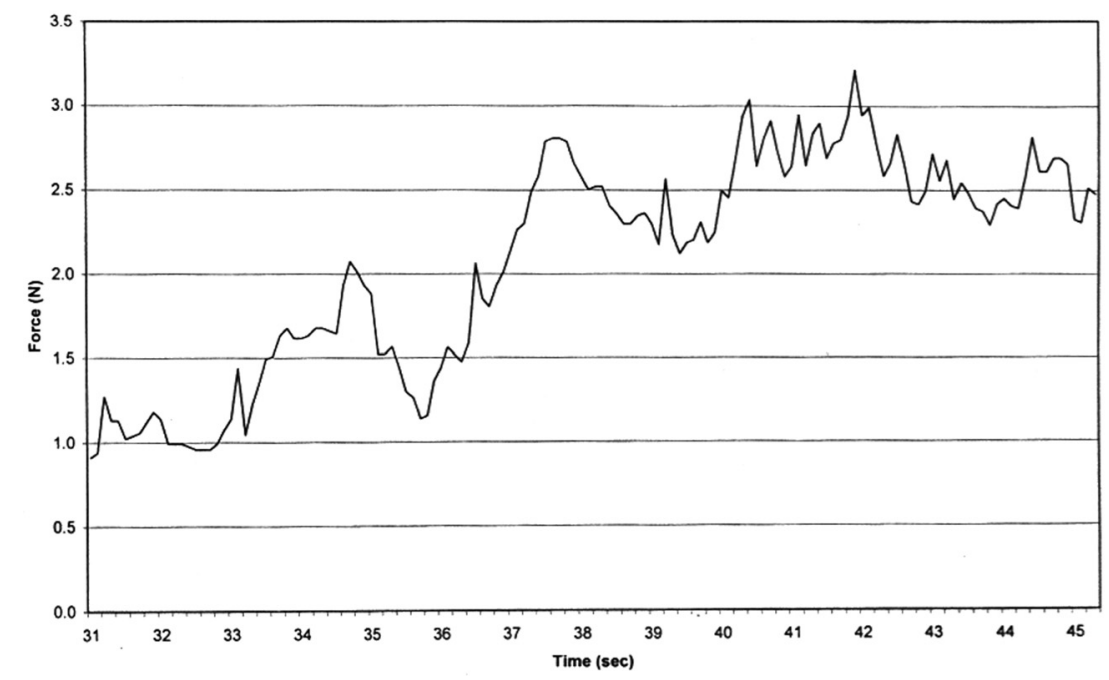

FIGURE 25. Liftoff force induced by engulfed bubbles: STS-57 Run \#8, $q^{\prime \prime}=4 \mathrm{~W} / \mathrm{cm}^{2}$, $\Delta T_{\text {sub }}=0.3^{\circ} \mathrm{C}$.

to prevent bubble contact with the opposing side. It is noted in FIGURE 15 that the liftoff force is virtually constant up to the maximum time shown, when the bulk liquid stirrer was turned on, producing the subsequent behavior seen in FIGURE 14.

The behavior of the experiments at the next lower heat flux level, $q^{\prime \prime}=4 \mathrm{~W} / \mathrm{cm}^{2}$, are shown in Figures 16-19 for a subcooling $\Delta T_{\text {sub }}=11.1^{\circ} \mathrm{C}$ and in FIGURES 20 and 21 for a subcooling $\Delta T_{\text {sub }}=3^{\circ} \mathrm{C}$. It is noted that, in Figures 17,19 , and 21 , for all three cases, the induced liftoff forces distinctly decrease with time, as the subcooling level decreases. This was also the behavior at the lower heat flux level, $q^{\prime \prime}=2 \mathrm{~W} / \mathrm{cm}^{2}$ and subcooling $\Delta T_{\text {sub }}=3^{\circ} \mathrm{C}$ in FIgURES 9 and 13. The exceptional behavior in FIGURE 11 for these parameters is discussed above.

Where the bulk liquid is initially almost at saturation, a quite different behavior takes place. Here the induced lift-off force either remains almost constant, as in FIGURE $6\left(q^{\prime \prime}=2 \mathrm{~W} / \mathrm{cm}^{2}, \Delta T_{\text {sub }}=0.3^{\circ} \mathrm{C}\right)$, or increases with time, as in FIGURE 23 $\left(q^{\prime \prime}=2 \mathrm{~W} / \mathrm{cm}^{2}, \Delta T_{\text {sub }}=0.3^{\circ} \mathrm{C}\right)$ and in Figure $25\left(q^{\prime \prime}=4 \mathrm{~W} / \mathrm{cm}^{2}, \Delta T_{\text {sub }}=0.3^{\circ} \mathrm{C}\right)$.

In interpreting the significance of the levels of the liftoff forces presented above, it is important to keep in mind the assumption made in the development of the analysis by which the forces were computed from the measurements: below Equation (1) it was assumed that the surface energy of each engulfed or combined small vapor bubble is completely (ideally) converted to kinetic energy. General experience indicates that some efficiency factor should be applied, which at this time is highly subjective, perhaps ranging from 1-50\%. It might be anticipated that a considerable expenditure of appropriate experiment effort (accompanied by analysis) will be needed to reduce this uncertainty. On physical and geometric grounds this efficiency could be expected to depend on the size of the engulfed bubble, a larger value for smaller bubbles. 


\section{CONCLUSION}

Among the total of 45 experiments conducted of pool boiling on a flat heater surface in the long-term microgravity of space, 26 somewhat unexpectedly resulted in steady-state pool boiling. Examination of 16-mm motion films showed that 9 of the 26 experiments were associated with the relatively high subcooling levels in which the resulting small vapor bubbles remained in the vicinity of the heater surface, with motion parallel to the surface caused by thermocapillary effects.

In the remaining 17 of 26 experiments, highly effective steady-state boiling took place when a large vapor bubble, slightly removed from the heater surface, was present to act as a reservoir for the small bubbles growing beneath. The momentum transfer of these small bubbles to the large bubble as they combine is believed to provide the force necessary to counter the thermocapillary force that otherwise would move the large bubble toward the heater surface, resulting in dryout. Measurements of the size and frequency of the small bubbles as they are engulfed by the large one provide estimates of the so called liftoff force that counters that of thermocapillarity. The maximum possible levels of this force have been determined to be on the order of $0.8-6.0 \mathrm{~N}$ for the experimental parameters used.

It was observed that where the initial bulk liquid was near saturation, the total liftoff force tended to increase with time, whereas for the initially subcooled bulk liquid case, the force tended to decrease with time.

\section{ACKNOWLEDGMENTS}

The results presented here were obtained using films produced under NASA Contract NAS 3-25812. The assistance of NASA and Dr. Francis P. Chiaramonte, the Project Scientist at the time, are gratefully acknowledged. The author thanks the students, Mr. Eric Preiditsch, Ms. Valerie Toth, and Mr. Shawn Burgdorf for the, at times, tedious task of measurements from the films.

\section{REFERENCES}

1. Merte, H., JR., H.S. Lee \& R.B. Keller. 1995. Report on pool boiling experiment flown on STS-47 (PBE IA), STS-57 (PBE-IB), STS-60 (PBE-IC). NASA Contract NAS 3-25812, Report No. UM-MEAM-95-01, Department of Mechanical Engineering and Applied Mechanics, University of Michigan, Ann Arbor, Michigan.

2. Merte, H., JR., H.S. LeE \& R.B. Keller. 1998. Dryout and rewetting in the pool boiling experiment flown on STS-72 (PBE-IIB), STS-77 (PBE-IIA). Final Report, NASA Grant NAG-1684, Report No. UM-MEAM-98-01, Department of Mechanical Engineering and Applied Mechanics, University of Michigan, Ann Arbor, Michigan.

3. Merte, H., JR., H.S. LeE \& J.S. Ervin. 1994. Transient nucleate pool boiling in microgravity—some initial results. Micrograv. Sci. Techn. VII/2: 173-179.

4. Lee, H.S., H. Merte, Jr. \& F. Chiaramonte. 1997. Pool boiling curve in microgravity. J. Thermophys. Heat Transf. 11: 216-222.

5. Lee, H.S., H. Merte, JR. \& F. Chiaramonte. 1998. Pool boiling phenomena in microgravity. Heat Transfer 1998. Proceedings of 11th IHTC, Vol. 2, August 23-28, 1998, Kyongju, Korea. 395-399.

6. Betz, J. \& J. Straub. 2002. Thermocapillary convection around gas bubbles. Ann. N.Y. Acad. Sci. 974: 220-245. 
7. SidES, P.J. 2002. A thermocapillary mechanism for lateral motion of bubbles on a heated surface during subcooled nucleate boiling. J. Heat Transf. 124: 1203-1206.

8. Merte, H., JR. \& H.S. LeE. 1997. Quasi-homogenous nucleation in microgravity at low heat flux: experiments and theory. J. Heat Transf. 119: 305-312.

9. LeE, H.S. \& H. MERTE. 1996. Spherical bubble growth in uniformly superheated liquids. Int. J. Heat Mass Transf. 39: 2427-2447.

10. LEe, H.S. \& H. MerTE. 1996. Hemispherical vapor bubble growth in microgravity: experiments and model. Int. J. Heat Mass Transf. 39: 2449-2461.

11. LeE, H.S. \& H. Merte, JR. 1998. The origin of the dynamic growth of vapor bubbles related to vapor explosions. J. Heat Transf. 120: 174-182.

12. Mastroianni, M.J., R.F. Stahl \& P.N. Sheldon. 1978. Physical and thermodynamic properties of 1,1,2-trifluorotrichloroethane (R-113). J. Chem. Eng. Data 23: 113-118. 